\title{
GBL for Psychological Intervention Related Skills: What Challenges? What Paths?
}

\author{
Carla Sousa $^{1}$, Micaela Fonseca ${ }^{1,2}$, Shivani Mansuklal ${ }^{1}$, Jéssica Carvalho ${ }^{1}$, Diogo Silva ${ }^{1}$, Pedro \\ Neves $^{1}$, Filipe Luz ${ }^{1}$, Ágata Salvador ${ }^{1}$, Leonor Costa ${ }^{1}$, Jorge Oliveira ${ }^{1}$ and Pedro Gamito ${ }^{1}$ \\ ${ }^{1}$ Lusófona University, Portugal \\ ${ }^{2}$ NOVA University Lisbon, Caparica, Portugal \\ carla.patricia.sousa@ulusofona.pt; micaela.fonseca@ulusofona.pt; shivani.mansuklal@ulusofona.pt; \\ mab4.jessica@gmail.com; diogo.silva55@hotmail.com; pedro.neves@ulusofona.pt; \\ filipe.luz@ulusofona.pt; agata.salvador@ulusofona.pt; leonor.costa@ulusofona.pt; \\ jorge.oliveira@ulusofona.pt; pedro.gamito@ulusofona.pt \\ DOI: 10.34190/GBL.21.097
}

\begin{abstract}
In recent research, games have become an important reference with regards to learning skills with certain characteristics, as well as in promoting contemporary literacies. Games have similarly become highly relevant in the promotion of psychological well-being and mental health. Even considering this role in promoting learning in general, soft skills, motivation, cooperation, empathy, among others, in the field of psychological intervention, the potential of games has been much more applied to patients than to the psychologists and their professional development. The present study aims at mapping the intersection between psychological intervention related skills learning and game-based pedagogical strategies. For such purpose, a Systematic Literature Review was conducted through some of the most relevant scientific databases. The obtained sample was further selected following the PRISMA guidelines with screening and eligibility processes based on inclusion criteria, defined considering the research's aim. Non-peer reviewed research and studies aimed at other pedagogical approaches, such as gamification, were excluded from the final sample. Papers were categorized, coded, and analysed through statistical procedures and content analysis techniques. The results contextualize games as effective and feasible tools in the professional development of psychologists and psychology graduates, simultaneously highlighting the scarcity of resources in this field and the need for more experimental and quasi experimental approaches to foster evidence-based pedagogical choices.
\end{abstract}

Keywords: GBL, Psychology, Psychology Learning, Psychology Students, Mental Health Professionals, Therapists

\section{Background}

Johan Huizinga (1944/1980, pp. 1-27) developed one of the first and most relevant conceptual approaches to play, framing it as much more than a simple physiological phenomenon or psychological reflex, highlighting its highly significant function that transcends life's immediate needs and attributes meaning to human actions. Moreover, Huizinga established the main characteristics of play, that include the concept of 'magic circle' - a material or figurative predefined space where play occurs. Inside such space, reality is suspended as well as all the external elements. This momentary suspension of reality is also crucial to foster an optimal experience, such as postulated in the highly widespread flow theory (Csikszentmihalyi, 1990/2008, pp. 23-42). Its ability to promote flow experiences has been studied as one of the crucial aspects of GBL approaches (Chang et al, 2017).

For Game-Based Learning (GBL), and even if it conflicts with other Huizinga's premises, namely the voluntary factor, the 'magic circle' can be better explained by a triad composed of challenge, response, and feedback. The player's learning process is then mediated by the set of implemented game design features, particularly the incentive system, the game mechanics (for learning and/or assessment), the aesthetic design, the narrative design, and the score (Plass, Homer and Kinzer, 2015). Considering its characteristics, GBL has been increasingly seen as a pedagogical tool able to support educational approaches based on some of the most relevant learning principles, including experiential learning, situated learning, and problem-based learning. Moreover, it is also relevant for several educational theories, with a special emphasis on constructivism (Wu et al., 2011).

In the last years, GBL has been extensively approached in educational research, sustained as an effective and feasible pedagogical strategy (All, Castellar and Looy, 2014; Jabbar and Felicia, 2015). These effects are nowadays expressive and extensive to some of psychology's main intervention areas, such as mental health (Fleming et al, 2017). Notwithstanding, the education of current or future psychology professionals seems to be a much less explored path. 


\section{Games and psychology education}

In 1958, Roger Caillois presented his perspective about the definition of play that is, to some extent, in line with the previously explored definition by Huizinga (1944/1980). For the author, play is defined by six formal attributes: free, separate, uncertain, unproductive, governed by rules, and based on 'make-believe'. Thus, to be considered play, an activity must be, among other aspects, performed without compulsion, accompanied by the notion of a second reality, opposed to 'real life' (Caillois, 1958/2001). This premise of games as a second reality can potentially establish a parallel with role-playing based techniques, frequent and highly relevant in psychology teaching, with a significant potential in the promotion of skills and empathy (Poorman, 2002).

Specific aspects of learning psychology also seem to present parallels with characteristics present in games as an emerging interactive medium. Salen and Zimmerman (2003, p. 300) establish the general definition that "play is free movement embedded in a more rigid structure". In the case of games, play occurs when their rules are set 'in motion' and experienced by the players, considering that this does not only come from the game itself, but from the way the player interacts with it. If we critically reflect on such definitions, we will be able to identify a clear parallel between the free movement embedded in a more rigid structure" (Salen and Zimmerman, 2003, p. 300) and the characteristics commonly inherent to anamnesis and semi-structured interviews in psychology, for example. Even psychotherapy can be seen as a "free movement" that occurs within a "more rigid structure", the adopted theoretical approach(es).

Therefore, it is possible to argue that the main characteristics of games that are crucial in the enhancement of learning processes, are even more central in the development of psychological intervention related skills: interaction; presence of other people within the learning process; rules; and safety (Whitton, 2009).

As a Systematic Literature Review (SLR), the present study aims at mapping the intersection between psychological intervention related skills learning and game-based pedagogical strategies, as an approach to explore the future challenges and opportunities in the field.

\section{Method}

\subsection{Eligibility criteria}

The rationale of the eligibility criteria was based on the main topics of the research question. Studies were included if they described GBL applied to psychology education. Furthermore, the inclusion criteria for the selection process was defined as the following: 1) empirical studies, 2) published in a peer-reviewed journal, 3) published in the English Language, 4) published from 2000 to the final search date 1st of April 2021, 5) only studies with humans. Likewise, the exclusion criteria were defined as: book chapter, book reviews, systematic reviews, and theoretical papers in any form; and those who considered the concept of Gamification as opposed to GBL.

\subsection{Information sources}

The search was conducted in electronic databases defined during the search strategy as: All Collections in Web of Science; EBSCO PsycINFO; PubMed; ERIC; IEEE Xplore and ACM Digital Library. The final search with the purpose of extracting all results from the databases was conducted on the 1st of April 2021.

\subsection{Search strategy}

In terms of the search strategy, the search equation was composed as the following: ("GBL" OR "game-based learning" OR "training skills" OR "educational game*" OR "simulation*" OR "virtual environment" OR "3D virtual*" OR "avatar" OR "virtual character" OR "virtual reality") AND ("psychology education" OR "psychology student*" OR "psychology undergraduate*" OR "psychology graduate*" OR "psychology trainee*").

The search was then conducted in the electronic databases with the search equation and filters were applied when possible. The results from Web of Science, EBSCO PsycINFO, PubMed, IEEE Xplore and ACM Digital Library were filtered by the year of publication, specifically 2000 onwards, while ERIC only permitted a filter for the last 20 years which led to results beginning at the year 2002. Only Web of Science, EBSCO PsycINFO and PubMed permitted the use of a filter for the English Language, and EBSCO PsycINFO and ERIC the use of a filter for only 
peer-reviewed. All results from the electronic databases were imported into reference management software Endnote $\mathrm{X} 9$.

\subsection{Selection process}

After importing the results, a feature of Endnote X9 was used to eliminate duplicates automatically. The results were then exported to a table in an excel sheet for the screening process. The first phase consisted of the screening of titles and abstracts of the studies to identify and label the studies as 'included' or 'excluded' in the table according to the inclusion and exclusion criteria. This process was conducted by three independent researchers and indecisions experienced during the screening were resolved by consultation with a fourth reviewer - CS. To summarise, SA screened in total 1026 studies, JC screened 850 studies and DS screened 774 studies in the first phase. The second phase consisted of full-text screening of the included studies of phase one. This was executed by CS and MF.

\subsection{Data extraction and analysis}

To analyse the selected papers, the sample was coded, to find the most relevant analysis categories, including sample, main objectives, aimed skills, game features, methodological approach, assessment, and results. After coding the 10 papers for each specific category, data was analysed through descriptive statistical analysis procedures. Finally, the obtained results were critically analysed and discussed by the team.

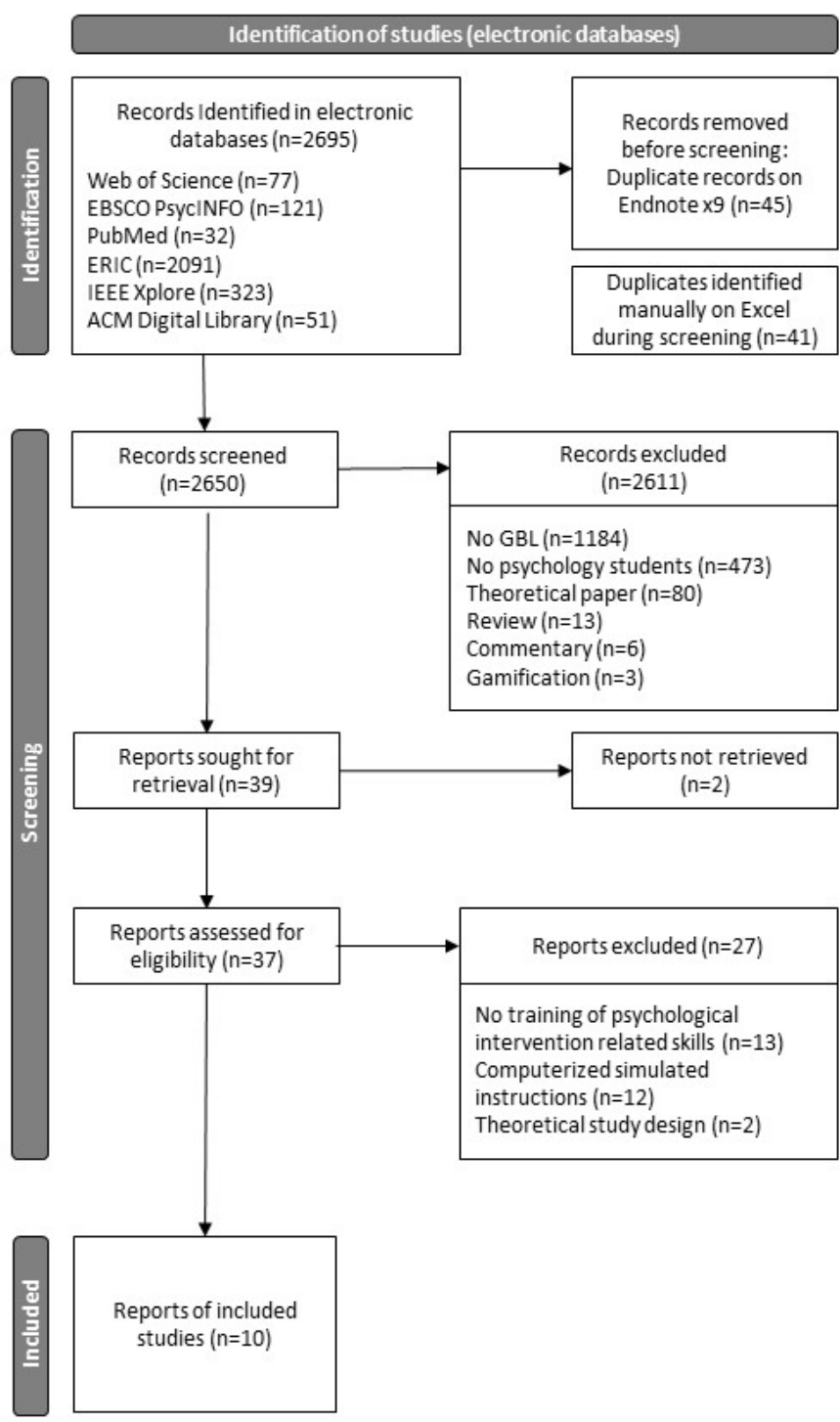

Figure 1: Flow diagram showing the process of the identification studies to include in the review 


\section{Results}

The initial database search returned 2650 studies, 86 duplicates were removed and from 39 included publications, 37 were retrieved in full for eligibility screening. Upon closer inspection, studies with computerized instructions without game elements and others focusing on skills promoted through games but not related with psychological intervention, were removed. Thus, 10 studies were included in the systematic review. All results obtained during the screening process are presented in Figure 1, and the content analysis summary is systematized in Table 1.

Table 1: Frequency and percentage of studies included in each coding category $(N=10)$

\begin{tabular}{|l|c|}
\hline Main Outcomes & Frequency of studies (\%) \\
\hline Methodological Approach & $4(40.00)$ \\
Qualitative Studies & $6(60.00)$ \\
Quantitative Studies & \\
\hline Subjects (N = 666; $\boldsymbol{M}=\mathbf{6 6 . 6} ;$ SD = 63.46) & $9(90.00)$ \\
Psychology Students & $1(10.00)$ \\
Mixed (psychologists and students) & \\
\hline Technique & $2(20.00)$ \\
Qualitative Feedback Gathering & $4(40.00)$ \\
Survey or questionnaire & $1(10.00)$ \\
In-game performance (metrics) & $2(20.00)$ \\
Validated Scales & $1(10.00)$ \\
Content analysis of essays & \\
\hline Assessment & $6(60.00)$ \\
Post Intervention & $2(20.00)$ \\
Performance (during intervention) & $1(10.00)$ \\
Performance and Post Intervention & $1(10.00)$ \\
Pre and Post Intervention & \\
\hline Study/Skill areas & $3(27.27)$ \\
General psychology knowledge & $2(18.18)$ \\
Social psychology & $1(9.09)$ \\
Community psychology & $1(9.09)$ \\
Interviewing skills & $1(9.09)$ \\
Educational psychology & $1(9.09)$ \\
Psychopharmacology & $1(9.09)$ \\
Abnormal psychology & $1(9.09)$ \\
Entrepreneurial applications of psychology & \\
\hline Game type used & $6(60.00)$ \\
Simulation & $1(10.00)$ \\
Puzzle & $1(10.00)$ \\
Role-playing & $2(20.00)$ \\
Set of games & $2(22.22)$ \\
\hline Developmental context of the game & \\
Specifically for research purposes & $2(20.00)$ \\
Commercial games & $5(50.00)$ \\
\hline Game platform type & \\
Digital & \\
Analog & \\
Mixed & \\
\hline Platform & \\
PC & \\
Several & \\
\hline
\end{tabular}

\subsection{Participants, games, and methodological approaches}

The present SLR has a combined sample of 666 subjects, with papers' samples ranging from three and $186(M=$ $66.6 ; S D=63.46)$. Most of the papers' samples were composed exclusively by psychology students $(N=9$; $90.00 \%)$. One paper studied a sample of both psychology students and psychologists (10.00\%).

Studies' research objectives mainly consisted in empirical approaches to the feasibility and/or effectiveness of game-based strategies to develop professional skills inherent to psychology, as systematized in Table 2. 
Moreover, studies frequently tended to also approach motivational and engagement factors inherent to the learning process.

Table 2: Studies' main objectives for the 10 studies selected for the systematic review

\begin{tabular}{|c|c|}
\hline Study & Main Objective \\
\hline 1 & $\begin{array}{l}\text { "We suggest that instructors using SL [refers to Second Life] formulate clear objectives, start with simple } \\
\text { activities, and involve their students in designing and assessing learning activities in the virtual world." (Baker, } \\
\text { Wentz and Woods, 2009, p. 99) }\end{array}$ \\
\hline 2 & $\begin{array}{l}\text { "This article provides some preliminary qualitative evidence regarding the use of Star Power, an exercise that } \\
\text { aims to increase student's knowledge and awareness of ecological perspectives on oppression. The purpose } \\
\text { of this article is to describe and discuss the benefits of Star Power." } \\
\text { (Nnawulezi et al, 2013, p.114) }\end{array}$ \\
\hline 3 & $\begin{array}{l}\text { "(...) to assess students' perceived effectiveness of the game in affecting their exam performance and study } \\
\text { habits and (b) to determine whether playing the game actually affected students' exam performance." (Paul, } \\
\text { Hollis and Messina, 2006, p. 276) }\end{array}$ \\
\hline 4 & $\begin{array}{l}\text { "(...) replicate the effects of feedback manipulation in a group of psychologists and to test if the acquired } \\
\text { skills transfer into interviews with actual children who witnessed a mock event, following previous studies." } \\
\text { (Pompedda et al, 2021, p. 46) }\end{array}$ \\
\hline 5 & $\begin{array}{l}\text { "The purpose of this study was to trial a virtual reality role-play experience where students played the role } \\
\text { of a student counsellor." (Rogers et al, 2020, p. 1) }\end{array}$ \\
\hline 6 & $\begin{array}{l}\text { "This article reviews six games used to teach a graduate psychopharmacology course, as well as students' } \\
\text { reactions to the GBL format." (Scarlet and Ampolos, 2013, p. 65) }\end{array}$ \\
\hline 7 & $\begin{array}{l}\text { "Therefore, the current work describes the creation, implementation, and assessment of the commercial of } \\
\text { the shelf game, The Sims } 3 \text { into an undergraduate social psychology course as a supplement to reading the } \\
\text { textbook." (Stansbury, 2017, p.126) }\end{array}$ \\
\hline 8 & $\begin{array}{l}\text { "We sought to investigate whether using VR technology to provide students with direct exposure to } \\
\text { evidence-based psychological treatment approaches might enhance their understanding of and appreciation } \\
\text { for such treatments." (Stark-Wroblewski et al, 2008, p. 344) }\end{array}$ \\
\hline 9 & $\begin{array}{l}\text { "This study compares online simulation in Second Life }{ }^{\circledR} \text { (Linden Labs, San Francisco, California, USA) with } \\
\text { equivalent face-to-face activities for three scenarios. The intention was that the three sets of activities would } \\
\text { increase participant awareness of how psychology is applied in relation to work-based contexts." (Ward et } \\
\text { al, 2016, p. 918) }\end{array}$ \\
\hline 10 & $\begin{array}{l}\text { "To that end, the purpose of this study was to explore how students experience concepts and theories taught } \\
\text { in a general psychology course when playing a board or video game of their choice." (Zielinski et al, 2019, p. } \\
\text { 56) }\end{array}$ \\
\hline
\end{tabular}

Considering the above set-out objectives and the paper analysis, it is possible to verify that GBL strategies are applied to a broad range of psychology fields and skills. General psychology knowledge was the most frequently approached in the sample $(N=3 ; 27.27 \%)$, followed by social psychology $(N=2 ; 18.18 \%)$. The rest of the studies approached a different learning area each $(N=1 ; 9.09 \%)$, including: community psychology, specifically "knowledge and awareness of ecological perspectives on oppression" (Nnawulezi et al, 2013); interviewing skills; educational psychology; psychopharmacology; abnormal psychology; and entrepreneurial applications of psychology. It is important to highlight that Paul, Hollis and Messina (2006) approach both general psychology and social psychology skills, justifying the existence of 11 coded subject areas for 10 studies. Moreover, it is also important to state that these skills are not necessarily mutually exclusive, and are mostly related but, for analysis purposes, they were considered as mentioned by the author(s).

Regarding the games used, and considering the classification developed by Grace (2005), simulation was the most prevalent game type $(N=6 ; 60.00 \%)$, followed by studies that used a set of games instead of only one game $(N=2 ; 20.00 \%)$. Regarding the developmental context of each game, half of the papers used games specifically developed for research purposes $(N=5 ; 50.00 \%)$. The rest of the sample made usage of commercial games for research purposes $(N=5 ; 50.00 \%)$. A higher usage of digital games was also found $(N=7 ; 70.00 \%)$, with only one analogical game (10.00\%), and two studies that mixed analogical and digital games $(20.00 \%)$.

The games specifically developed for research purposes were mainly simulations associated with a psychologists' professional practice, with two of them using Virtual Reality (VR) as the main technology (Paul, Hollis and Messina, 2006; Pompedda et al, 2021; Rogers et al, 2020; Stark-Wroblewski et al, 2008). The exception was the study developed by Scarlet and Ampolos (2013), where a set of specifically developed quizzes, puzzle, and board games were adapted and used as a support tool to foster students' engagement in psychopharmacology classes. 
The commercial games used in the studies included Second Life (Baker, Wentz and Woods, 2009; Ward et al, 2016), StarPower (Nnawulezi et al, 2013), The Sims 3 (Stansbury, 2017), Clash of Clans, Club Penguin, FIFA, Hedbandz, League of Legends, Madden 16, and Minecraft (Zielinski et al, 2019).

Regarding the adopted methodological approaches, and with exception of the study developed by StarkWroblewski et al (2008), there was an absence of studies adopting experimental or quasi experimental approaches. Considering this, studies were classified by the nature of the collected data, the assessment strategy, and the data collection techniques. Most of the sample was composed of quantitative studies $(N=6$; $60.00 \%)$, with other four studies adopting more qualitative approaches ( $N=4 ; 40.00 \%)$. Most of the studies also adopted only post intervention assessment of learning outcomes ( $N=6 ; 60.00 \%)$, while two studies adopted assessments during the game, such as performance indicators (20.00\%). Regarding the techniques adopted for assessment, surveys and questionnaires appear as the most frequent ( $N=4 ; 40.00 \%)$. As above mentioned, the summary of these results is presented in Table 1.

\subsection{Main insights from the sample}

Considering the diversity of objectives presented by the selected studies, as seen in table 1, a similar multiplicity of conclusions was expected. Baker, Wentz and Woods (2009) highlighted that game-based approaches in psychology learning entail both drivers, such as the potential for fostering student engagement, and barriers, including the time required to get familiar with the technology, and other technological issues. Through the analysis of the gathered feedback, Nnawulezi et al (2013) discussed the effectiveness of StarPower, considered by them as a powerful method to promote ecological thinking about social injustice, which is crucial for professionals in the field of community psychology. This conclusion is similar to the formulated by Paul, Hollis and Messina (2006) but, in their case, for learning more general concepts in the field of psychology. Pompedda et al (2021) also supports the effectiveness of GBL in the field, specifically for interviewing skills, highlighting that this solution decreases time and financial costs of training, allowing a nature of practical experimentation that is impossible in information-based learning. Besides supporting GBL effectiveness, Rogers et al. (2020) also highlighted the feasibility of this pedagogical strategy, discussing its potential inclusion in the curriculum and how this could enhance students' experience in undergraduate psychology courses. The integration of innovative pedagogies, such as GBL, could represent a relevant strategy to enhance the learning process in some specific subjects in the field of psychology, where training is inadequate and ineffective, such as psychopharmacology (Scarlet and Ampolos, 2013). Considering more specific results, a learning format that goes beyond the traditional lecture is suggested as relevant to improve comprehension, higher order thinking skills, and learning outside the classroom (Stansbury, 2017), improving students' satisfaction and insight of their own learning process (Stark-Wroblewski et al, 2008). Through critical reflection and implementation of general psychology concepts and theories to different commercial games, GBL effectiveness was also shown, with learning outcomes that included brain, sensation, perception, human development, learning, motivation, intelligence, personality, and psychological disorders. From this, brain related knowledge and motivation theories were those that stood out the most, in terms of positive outcomes (Zielinski et al, 2019).

\section{Discussion}

The focus of this SLR was to map the intersection between psychological intervention related skills learning and game-based pedagogical strategies, as an approach to explore the future challenges and opportunities in the field. The systematic search demonstrates a very limited number of studies $(N=10)$ on this particular subject for the defined year range (2000-2021), and the number of results screened ( $N=2650)$. Also, through the search process, a problem regarding abstracts based on ambiguous and wide conceptualizations in the field of games created barriers to the clear distinction between GBL approaches and other disparate ones, such as simulation or gamification. Actually, the distinction between simulation and games in psychology training has shown crucial relevance in researching this field. Both concepts are used almost interchangeably and the selection of GBL approaches was a challenging process. A possible reason for this seems to be associated with the answer to the controversial question "what is a game", frequently answered in the obtained samples through a broad and undefined lens. Moreover, a confusion between games for psychological wellbeing and games for psychology learning was notorious.

Through this SLR games were analyzed as potentially relevant tools to support the learning of a wide range of skills associated with the professional exercise of psychology. Nevertheless, studies in the sample presented significant heterogeneity in adopted research methods and techniques, affecting the conclusions from the present study. There is a need to express the challenge occurring in the conduction of educational studies and 
learning interventions in general: high heterogeneity regarding study designs exists as the gold standard RCT's are rarely applicable in this context and quality assessment regarding the methodology used (Reed et al, 2005).

The games used to teach psychology are peculiarly diverse. If research in GBL is normally based on games specifically developed for each study (Costa, Tyner, Henriques and Sousa, 2016), in the analysed sample commercial games were also prominent. Studies with critical approaches to GBL, like analysing the gameplay of commercial games to find specificities of psychological processes were an unexpected finding. Such aspect seems to highlight the potential of psychological processes as a tool to analyse games, support their development, and enhance human-game relationship, framed on a so-called "Psychology of Videogames" (Hodent, 2021). Another relevant result regarding the used games is that most of the papers only briefly explored game features and game design aspects, reinforcing a gap between empirical papers in the field of behavioural sciences and game design/development papers, that seems to pose a barrier to studies' replicability.

\subsection{Limitations of the field}

Games research is, by definition, a multidisciplinary field with all the affordances and constraints this condition entails. To study games researchers frequently adopt an ideological and methodological position, associated with their background (Frasca, 2007, p. 41). One of the most prominent limitations related to this aspect is that studies usually adopt a specific framing, highlighting a gap between the ones that assess games effectiveness, the ones that explore the learning process, and the one's discussing game design aspects. Such limitations should be answered by teams as multidisciplinary as the field itself.

A further limitation of these pedagogical approaches concerns the potential discrepancy between simulation and real-life contexts, raising the problem of skills transferability (Pompedda et al, 2021). Also, the differences between the relationship with a human and the relationship with an artificial agent, such as an avatar or a NonPlayable Character (NPC), imposes restrictions circumscribed to a predefined behavioural repertoire. Mismatched behavioural responses from the artificial agent could be frequent, greatly impairing immersion and thus the learning process (Rogers et al, 2020).

The individual differences of students (Stansbury, 2017) should be taken as a caution when interpreting the results presented, as they influence their in-game behaviour, learning style, and gains. Sometimes there may even be resistance in accepting methods such as GBL, given the expectation of learning based on more passive and traditional approaches (Stark-Wroblewski et al, 2008). The individual differences and of each university setting, together with the specificities of the research designs presented, which exclude the existence of a control group, make the results presented difficult to generalize (Stark-Wroblewski et al, 2008; Ward et al, 2016).

The lack of approaches including graduate students or psychologists also poses an issue, making the present results better suited to undergraduate psychology students and basic curriculum elements and subjects.

\section{Conclusion and future directions}

Notwithstanding the above discussed challenges and limitations, the present work justifies games as an engaging strategy to teach psychology. GBL provides psychology students with an environment where they receive constant feedback on their performance and errors have low human costs. The ethical issues posed by training psychologists and psychology students could be easily overcome by simulation, but only game features could also provide competition, challenge, exploration, fantasy, goals, interaction, outcomes, people, rules, and safety (Whitton, 2010, p. 33).

Through the present study, a main crucial direction for the future emerges, centralized in the need to develop more studies in this field, namely experimental and quasi experimental studies that further support the effectiveness of GBL as a pedagogical approach to psychology learning. Moreover, studies combining both this type of evidence and detailed data on game design and game development processes are crucial to a better knowledge of the relationship between game mechanics and learning, making conclusions replicable.

Considering what has been discussed, it is possible to highlight the potential that GBL could bring to the future of psychology learning, since it constitutes a form of training where the high psychosocial risks of training with humans do not arise. In this sense, future studies could address feasibility and effectiveness of this approach, in an experimental or quasi-experimental way, in a wider range of areas of the psychology curriculum, including "understanding psychological principles" (Zielinski et al, 2019), “consultancy skills" (Ward et al, 2016), 
"demonstrating symptoms of a disorder, teaching communication strategies, self-reflection, and assessment purposes" (Rogers et al, 2020). Another area that should be further explored by research is "the relationship between GBL effects and metacognitive processes that may affect students' perceptions of learning and perceived satisfaction with the learning environment" (Stansbury, 2017).

\section{Acknowledgements}

The present study was developed in the scope of VRMnesis - HEILAB/SEEDILIND, co-funded by the "Fazer+" programme of Instituto Lusófona de Investigação e Desenvolvimento (ILIND; https://investigacao.ulusofona.pt/). The work was also co-funded by Fundação para a Ciência e Tecnologia (FCT), under HEI-Lab center (UIDB/05380/2020).

\section{References}

All, A., Castellar, E.P.N. and Looy, J.V. (2014) 'Measuring Effectiveness in Digital Game-Based Learning: A Methodological Review.', International Journal of Serious Games, 1(2), pp. 1-8 [online]. Available at: http://dx.doi.org/10.17083/ijsg.v2i4.98

Baker, S.C., Wentz, R.K. and Woods, M.M. (2009) 'Using virtual worlds in education: Second Life ${ }^{\circledR}$ as an educational tool', Teaching of Psychology, 36(1), pp. 59-64 [online]. Available at: https://dx.doi.org/10.1080/00986280802529079

Caillois, R. (2001) Man, play and games. Translated by Barash, M. Republished, Illinois: University of Illinois Press, 1958.

Chang, C., Liang, C., Chou, P., and Lin, G. (2017) 'Is game-based learning better in flow experience and various types of cognitive load than non-game-based learning? Perspective from multimedia and media richness', Computers in Human Behavior, 71, pp. 218-227 [online]. Available at: https://doi.org/10.1016/j.chb.2017.01.031

Costa, C., Henriques, S., Tyner, K. and Sousa, C. (2016) 'A Review of Research Questions, Theories and Methodologies for Game-Based Learning', Journal of Content, Community and Communication, 4 [online]. Available at: https://www.amity.edu/gwalior/jccc/december2016.html

Csikszentmihalyi, M. (1990) Flow: The Psychology of Optimal Experience. Republished, New York: Harper Perennial Modern Classics, 2008.

Fleming, T.M., Bavin, L., Stasiak, K., Hermansson-Webb, E., Merry, S.N., Cheek, C., Lucassen, M., Lau, H.M., Pollmuller, B. and Hetrick, S. (2017) 'Serious Games and Gamification for Mental Health: Current Status and Promising Directions', Frontiers in Psychiatry, 7, pp. 1-7 [online]. Available at: https://doi.org/10.3389/fpsyt.2016.00215

Frasca, G. (2007) Play, Game and Videogame Rhetoric, Ph. D. Dissertation. IT University of Copenhagen. Available at: https://www.yumpu.com/en/document/read/11225449/frasca-play-the-message-phd (Accessed: November 2020)

Grace, L. (2005) Game Type and Game Genre [online]. Available at: https://professorgrace.com/documents/guides/Game types and genres.pdf (Accessed: 24 april 2021)

Hodent, C. (2021) The Psychology of Video Games. $1^{\text {st }}$ edn. [online]. Available at: https://doi.org/10.4324/9781003045670

Huizinga, J. (1944). Homo Ludens: a study of the play-element in culture. Reprint, Great Britain: Redwood Burn Ltd, 1980.

Jabbar, A.I.A. and Felicia, P. (2015) 'Gameplay Engagement and Learning in Game-Based Learning: A Systematic Review', Review of Educational Research, 85(4), pp. 740-779 [online]. Available at: https://doi.org/10.3102/0034654315577210

Nnawulezi, N., Campbell, C., Landstra, K., Davis, S.A., Vandegrift, C. and Taylor, A. (2013), 'Star power: An experiential learning exercise to foster ecological perspectives on power privilege, and oppression', Journal of prevention \& Intervention in the Community, 41(2), pp. 113-120 [online]. Available at: https://doi.org/10.1080/10852352.2013.757988

Paul, S.T., Hollis, A.M. and Messina, J.A. (2006) 'A Technology Classroom Review Tool for General Psychology', Teaching of Psychology, 33(4), pp. 276-279 [online]. Available at: https://journals.sagepub.com/toc/topa/33/4

Plass, J.L., Homer, B.D. and Kinzer, C.K. (2015) 'Foundations of Game-Based Learning', Educational Psychologist, 50(4), pp. 258-283 [online]. Available at: https://doi.org/10.1080/00461520.2015.1122533

Pompedda, F., Palu, A., Kask, K., Schiff, K., Soveri, A., Antfolk, J. and Santtila, P. (2021) 'Transfer of simulated interview training effects into interviews with children exposed to a mock event', Nordic Psychology, 73(1), pp. 43-67 [online] Available at: https://doi.org/10.1080/19012276.2020.1788417

Poorman, P.B. (2002) 'Biography and Role Playing: Fostering Empathy in Abnormal Psychology', Teaching of Psychology, 29(1), pp. 32-36 [online]. Available at: https://journals.sagepub.com/toc/topa/29/1

Reed, D., Price, E.G., Windish, D.M., Wright, S.M., Gozu, A., Hsu, E.B., Beach, M. C., Kern, D. and Bass, E.B. (2005) 'Challenges in Systematic Reviews of Educational Intervention Studies', Annals of Internal Medicine, 142(2 pt.2), pp. 1080-1089 [online]. Available at: https://doi.org/10.7326/0003-4819-142-12 Part 2-200506211-00008

Rogers, S.L., Hollet, R., Li, Y.R. and Speelman, C.P. (2020) ‘An Evaluation of Virtual Reality Role-Play Experiences for HelpingProfession Courses', Teaching of Psychology [online]. Available at: https://doi.org/10.1177\%2F0098628320983231

Salen, K. and Zimmerman, E. (2003). Rules of Play: Game Design Fundamentals. Cambridge, Massachusetts: The MIT Press.

Scarlet, J. and Ampolos, L. (2013) 'Using Game-based Learning to Teach Psychopharmacology', Psychology Learning and Teaching, 12(1), pp 64-70 [online]. Available at: http://dx.doi.org/10.2304/plat.2013.12.1.64

Stansbury, J.A. (2017) 'Virtual Learning Environments in Social Psychology: Using The SIMs ${ }^{3}$ to Teach Self-Related Processes', Teaching of Psychology, 44(2), pp. 124-133. 
Stark-Wroblewski, K., Kreiner, D.S., Boeding, C.M., Lopata, A.N., Ryan, J.J. and Church, T.M. (2008) 'Use of Virtual Reality Technology to Enhance Undergraduate Learning in Abnormal Psychology', Teaching of Psychology, 35(4), pp. 343-348 [online]. Available at: https://dx.doi.org/10.1080/00986280802374526

Ward, T., Falconer, L., Frutos-Perez, M., Williams, B., Johns, J. and Harold, S., (2016) 'Using Virtual online simulations in Second Life ${ }^{\circledR}$ to engage undergraduate psychology students with employability issues', British Journal of Educational Technology, 47(5), pp. 918-931 [online]. Available at: https://doi.org/10.1111/bjet.12307

Whitton, N. (2009) Learning with Digital Games: A Practical Guide to Engaging Students in Higher Education. $1^{\text {st }}$ edn. Oxfordshire: Routledge.

Wu, W. H., Hsiao, H. C., Wu P. L. , Lin, C. H. and Huang, S. H. (2011). 'Investigating the learning-theory foundations of game-based learning: a meta-analysis', Journal of Computer Assisted Learning, 28(3), pp. 265-279. Available at: https://doi.org/10.1111/j.1365-2729.2011.00437.x

Zielinski, D. (2019) 'Can playing games help students master concepts from general psychology classes?', International Journal of Game-Based Learning, 9(2), pp. 55-72 [online]. Available at: https://dx.doi.org/10.4018/IJGBL.2019040104 